CORRESPONDENCE

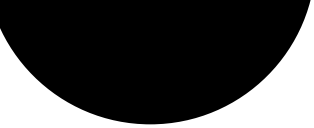

Correspondence should be sent to ip@rcpsych.ac.uk

\section{New directions in psychiatry - defining the way}

Sir: Psychiatry as a discipline will undergo major changes over the next few years. Although such changes can be stimulating and challenging from intellectual, scientific and social viewpoints, the new generations of psychiatrists must be prepared for them.

Paradigms which have represented the foundations of psychiatry in the last century are now in need of major revision. In particular, young psychiatrists feel the need: (1) to rediscover psychopathology in order to improve their diagnostic skills; (2) to adopt a preventive approach to psychiatry, intervening in the early stages of psychiatric disorders; (3) to improve their skills in conducting research and writing scientific papers; (4) to refine their knowledge of the biological and social determinants of mental illness.

All this was debated at the congress 'New Directions in Psychiatry', organised by the Early Career Psychiatrists Committee of the European Psychiatric Association (EPA) at Sorrento (Naples) on 21-23 May 2012 and dedicated to the needs of European early-career psychiatrists. More than 400 young colleagues from almost all European countries attended the congress, at which prominent European scientists gave their views on the future of mental healthcare.

The scientific track was organised as five thematic areas. The first session dealt with the future of psychiatry and mental health, and contributors were three past or future Presidents of the World Psychiatric Association, namely Professors Maj, Sartorius and Bhugra. The second session was dedicated to preventive psychiatry, in particular to early intervention in psychoses, prevention of suicide and management of perinatal depression. Speakers were Professors Birchwood, Wasserman and Bassi, respectively. The third session was dedicated to early-career psychiatrists' needs in the area of psychiatric diagnosis and classification, with contributions from Professor Sass on the role of psychopathology, Professor Galderisi on the role of the neurosciences and Professor Kastrup on the role of culture. The fourth session was dedicated to research in mental health. Professors Goldberg, Boyer and Gorwood provided practical tips and basic knowledge on the whole process of research and publication. The last session was dedicated to expectations for the future in biological and social psychiatry, with two of the most renowned European experts in the fields, namely Professors Kasper and Priebe.

Besides the plenary sessions, workshops, sponsored symposia, courses in continuing medical education (CME) and poster sessions were also organised. The two workshops dealt with the role of biomarkers in diagnosis and treatment, and with the relevance of psychopathology for clinical practice. During the sponsored symposia, new directions in the management and treatment of the three major mental disorders (schizophrenia, bipolar disorder and major depression) were discussed with several experts and speakers. Also, three CME courses were organised in collaboration with the Committee on Education of the European Psychiatric Association.

Finally, an interactive poster session was organised with 114 accepted posters. The three best posters received an award from the organising committee.

The congress was highly appreciated by both young and senior participants, and represented the basis for a fruitful discussion on how to improve psychiatric practice and training for the new generations in psychiatry.

\section{Andrea Fiorillo}

Department of Psychiatry, University of Naples SUN, Naples, Italy; Chairman, EPA Early Career Psychiatrists Committee, email anfioril@tin.it

\section{A challenge of the 21st century: brain migration in psychiatry}

Sir: There is an ongoing debate on the migration of healthcare professionals from lower-income to higher-income countries. These movements involve the loss and gain of health resources and the modification of the capacity of the health systems to deliver healthcare, and thus the achievement of the Millennium Development Goals (Global Health Workforce Alliance, 2008).

The concern over migration, as a challenge of the 21st century, has moved to the forefront of agendas and raises many questions. Changes such as globalisation, increased mobility, population ageing, the financial crisis and social networking are forcing us to test old views and adapt to new realities: honour or endurance, identity or governance, quantity or quality, innovation or stability, rights or duties, facts or judgements. These interrogations reflect differences of perception created by the great velocity and intensity of change, along with an unprecedented degree of interconnectivity and a lowering of international barriers (Spencer, 2011).

Defining migration is controversial, since it involves both space and time, which currently are continuously in evolution. Although the terminology has been criticised for its ambiguity, it is worth looking for actual and future migration in the new global context, even though it is a difficult task, by recognising the push factors that pressure people to leave the donor country, and the pull factors that make the recipient country seem attractive (Gureje et al, 2009), while confirming patterns and duration of migration. Connecting such data with the burden of illness and relating them to perceived stigma and experiences of discrimination might act as an input to influence healthcare policy stakeholders to support the planning processes according to current needs and the present use of treatment and services (Prince et al, 2007).

Is it a brain gain or a brain drain? In addition to the health dimension, brain migration has a cultural, economic, educational, financial and 
social impact, and affects the world as a whole: low-, middle- and high-income countries. The effects arising are both benefits and burdens in the country of destination or origin (Jenkins et al, 2010). Thus, it can be assumed that this migration will affect health services and care in some countries, especially if there is no support for the people who do migrate.

Unfortunately, there is lack of data on migration flows, as significant highly skilled migration has been within the European Union and, additionally, there is a particular scarcity of data in psychiatry (Gureje et al, 2009). Therefore, as an attempt to explore the extent of migration among psychiatry trainees, the European Federation of Psychiatry Trainees (EFPT) Research Group is doing a survey on brain migration to assess opinions on and experiences of international migration. The data will permit further comparison with other groups, such as physicians in general and psychiatric consultants.
Migration within psychiatry will probably continue. It is therefore essential to enhance support for those who do migrate and influence the mental healthcare provided internationally.

\section{Mariana Pinto da Costa}

Chair of the European Federation of Psychiatry Trainees (EFPT) Research Group, Email: mariana.pintodacosta@gmail.com

Global Health Workforce Alliance (2008) Scaling Up, Saving Lives - Taskforce for Scaling Up Education and Training for Health Services. See http://www.who.int/workforcealliance/documents/ Global_Health \% 20FINAL \% 20REPORT.pdf (accessed June 2012). Gureje, O., Hollins, S., Botbol, M., et al (2009) Report of the WPA Task Force on Brain Drain. World Psychiatry, 8, 115-118.

Jenkins, R. , Kydd, R., Mullen, P. et al (2010) International migration of doctors, and its impact on availability of psychiatrists in low and middle income countries. PLOS ONE, 5(2), e9049.

Prince, M. , Patel, V., Saxena, S., et al (2007) No health without mental health. Lancet, 370, 859-877.

Spencer, C. (2011) Global Issues of the Twenty-First Century and United Nations Challenges: A Guide to Facts and Views on Major or Future Trends. See http://www.global-challenges.org (accessed 8 October 2011).

\section{Contents of the Arab Journal of Psychiatry} (affiliated journal)

Volume 23 Number 1 May 2012

\section{Short report}

1 Refugee and asylum seeker children Dinesh Bhugra

\section{Original papers}

3 Prevalence of social phobia among preparatory school students in Duhok City, Iraq

Nazar M. Mohammad Amin, Perjan Hashem Taha

12 Predictors of psychiatric early readmission in two Arab hospitals El-Sayed Saleh, Mohamed Adel El-Hadidy

22 Prevalence and correlates of physical and sexual assault history in patients with schizophrenia

Mostafa Amr, Mahmoud El-Wasify, Tarek Amin, Alec Roy

30 Prevalence of mental health disorders among health care providers in the Psychiatric Hospital Bahrain

Haitham Jahrami, Zahra Al-Shuwaikh, Gnanavelu Panchasharam, Zahraa Saif

35 The effect of religious and spiritual beliefs on the quality of life among university students in Jordan measured by the modified version of (WHOQOL-SRPB) instrument Maha S. Younis, Ahmed S. Al-Noaimi, Mohammad H. Al-Dabass

41 Attitude of medical students towards psychiatry in the University of Jordan

Radwan A. BaniMustafa, Awni D. Shahait, Hanan K. AlOmari

\section{Liaison psychiatry}

46 Psychosocial background of disability in patients with chronic low back pain

H. Hamed, O. Raafat, M. Nasreldin, S. Abolmagd, A. El Awar

52 Neuro-chemical distortions among patients with leukaemia receiving chemotherapy

Hani Hamed, Noha Abdel Shafy, RandaKaddah

60 Neuropsychiatric complications following liver transplantation Mohamad Ezzat Amin, Faisal Abd El-Wahab

\section{Psychiatric education}

69 Objective structured clinical examination (OSCE) during psychiatry clerkship in a Saudi university Mostafa Amr, Dahoud Raddad, Zeinab Afifi

\section{Psychology}

74 Adult attachment styles in a Lebanese community sample: a brief Arabic experience in Close Relationships Scale Shahé S. Kazarian, Dana Taher

\section{Arabic paper}

86 The relationship between posttraumatic stress disorder and time perspective Slimane Djarallah, Mohamed Seghir Chorf

\section{Arab Journal of Psychiatry (2012) \\ vol. 23 no. 1 supplement on ICD-11}

1 The state of science in mental and behavioral disorders in the Arab region: research needs and relevance to classification Walid Sarhan

12 The classification of mental disorders in primary health care in the Arab region

Basem Saab, Suhaila Ghuloum, Yasmine Fayad

17 Intellectual developmental disorders, a forgotten disease in the Arab countries Leyla Akoury-Dirani

23 Dementia in the developing world; no place for complacency Saad F. Ghalib

28 Problems in applying diagnostic concepts of PTSD and trauma in the Middle East Abdelhamid Afana

35 Classification of sexual dysfunctions in the Arab world in relation to ICD-11 Brigitte Khoury, Elham Attallah, Yasmine Fayad

42 Is the diagnostic prototype for anorexia nervosa universal? Evidence from the Middle East and implications for ICD-11 Samir Al-Adawi, Atsu S. S. Dorvlo, Nonna Viernes, P. C. Alexander, Ibrahim Al-Zakwani 